\title{
TACIT LABOURS OF DIGITAL SOCIAL RESEARCH AS AN EARLY CAREER RESEARCHER
}

\author{
Crystal Abidin*
}

\begin{abstract}
Consider this essay as two brief confessions on the pressures of conducting 'digital social research' as an Early Career Researcher. Specifically, the confessions call out two emergent norms in academia: that early career digital social researchers ought to be visible and trackable online, and that we ought to focus on novel and innovative phenomena pioneered by 'the youngs'. These two expectations have insidiously been integrated into early career digital social researchers' repertoires of 'tacit labours' - "a collective practice of work that is understated and under-visibilized from being so thoroughly rehearsed that it appears as effortless and subconscious." (Abidin 2016, p. $10)$ - in that it is assumed that being 'Extremely Online' and 'Young <tm>' are generational literacies 'naturally' hardwired into our systems.
\end{abstract}

* Curtin University, Australia. 
Consider this essay as two brief confessions on the pressures of conducting 'digital social research' as an Early Career Researcher. Specifically, the confessions call out two emergent norms in academia: that early career digital social researchers ought to be visible and trackable online, and that we ought to focus on novel and innovative phenomena pioneered by 'the youngs'. These two expectations have insidiously been integrated into early career digital social researchers' repertoires of 'tacit labours' - "a collective practice of work that is understated and undervisibilized from being so thoroughly rehearsed that it appears as effortless and subconscious." (Abidin 2016, p. 10) - in that it is assumed that being 'Extremely Online' and 'Young <tm>' are generational literacies 'naturally' hardwired into our systems.

The first confession is that scholars and the academy are generating paraprestige economies that proffer sociable metrics as a mark of 'good' or 'successful' research. Young scholars like myself are constantly being told to establish the visibility of our portfolios in order to secure academic jobs that are increasingly competitive, scarce, and precarious. Where some aspiring academics still attend networking sessions across continents to practice our elevator pitches to rotations of acquaintances over cocktails and finger food, these days it feels as if the 'networking' is increasingly digitized. As the systems of visibility and status symbols of what counts as a 'successful' researcher develop over the years, even senior scholars sit through sessions with librarians on the importance of ORCIDs (Open Researcher and Contributor ID), DOIs (Digital Object Identifiers), Google Scholar profiles, and the world of academic social networking such as Academia.edu and ResearchGate in order that we be traceable, searchable, discoverable. Academic success is often crassly measured through digital visibility and quantifiable metrics including citation rates, article downloads, media coverage, and even 'alt-metrics' on social media. And what eventuates is a cult of digital sociability.

Scholars have long been intrigued with the practice of high visibility in academia, even conducting research into the histories and career trajectories of 'dominant' (Lamont 1987) and 'internationally famous' (Clegg 1992) scholars. So pertinent is visibility to a successful academic career that scholarly opinion editorials are publishing 'how to' guides (Tickle 2012), contemplating the importance of being visible (Shea 2014; Walsh 2015), and considering the drawbacks of highly visible academic celebrities (DuBois 2012; Miles 2012). While there are no quick solutions to 'the visibility games', senior scholars who have influence over institutional agenda setting can help to recalibrate the importance of 'social media presence' from the public, popular, and populist, to the communal, community, and civic, giving weight to the more qualitative and tangible experiences of social good.

The second confession is that (time-pressured) scholars are provoking the feedback loop of disproportionate information amplification between journalism and academia. This frustration stems from the cycle of: a) journalists scouting through social media content in search of potential news angles, albeit limited by the filter bubble of algorithmic recommendation systems tailored to their digital footprints 
and pet interests $\rightarrow$ b) journalists churning out popular media articles focused on emergent or obscure aspects of (especially youth) internet cultures, often framed to play up a sense of exotica to generate more pedestrian interest or to serve as clickbait $\rightarrow$ c) academics collating such popular media and news articles as data sets for content analysis as if they are representative of the state of digital or social trends $\rightarrow$ d) academics relying on the content analyses of such 'public data' to churn out publications, since it is more accessible than other time- and resource-intensive methods in the climate of 'publish or perish' $\rightarrow$ e) journalists' pet interests or observations becoming institutionalised as scientific truths (of sorts) through academics' publications of such analyses.

As a result, journalists eventually emerge as the gatekeepers and vanguards of how academia documents and investigates digital phenomena, and the cycle routinely and systemically supresses the variety and depth of digital cultures which is overshadowed by populist perceptions that are ultimately framed to maintain viewer traffic for commerce. This is all the more troubling when journalists without area- and culture-specific expertise surmise digital phenomena via ethnocentric lenses - as was the case in the global reportage of the MeituXiuxiu photo editing app during its virality in January 2017, that was distilled as "weird", "bizarre", and “alien” (wishcrys 2017). Following social theorist Raewyn Connell's call to Southern Theory (2014, p. 218), we ought to judiciously scrutinise what we consider "mainstream literature in a field of practice" to uncover in our process of knowledge production a "northern dominance of the discourse, and extraversion in the global south". To offset this, initiatives to lubricate journalists' access to scholarly insight and maintain digital social 'research' have resulted in databases cataloguing details of academic available for public commentary, such as Expert Connect (2019) in Australia and Science Media Center (2019) in Germany. Academics have also been encouraged to publish public-facing, popular media versions of our research on informed news outlets such as The Conversation and The Guardian, although the drawback is that such labour is usually uncompensated and can disproportionately disadvantage precarious sessional staff who cannot sustain themselves on 'exposure dollars'.

As we launch the Journal of Digital Social Research, may we also contemplate the uneven tacit labours involved in digitizing and socializing research.

\section{ACKNOWLEDGEMENTS}

I would like to thank Evelyn Runge for alerting me to the Science Media Center initiative in Germany, and Gabriele de Seta and Megan Lindsay Brown for shaping my insights through our collaborations and friendship. 


\section{REFERENCES}

Abidin, C. (2016) 'Aren't these just young, rich women doing vain things online?: Influencer selfies as subversive frivolity', Social Media + Society, 2(2), https://doi.org/10.1177/2056305116641342

Clegg, S. (1992) 'Review article: How to become an internationally famous British social theorist', The Sociological Review, 40(3), pp. 576-598, https://doi.org/10.1111/j.1467-954x.1992.tb00403.x.

Connell, R. (2014) 'Using southern theory: Decolonizing social thought in theory, research and application', Planning Theory, 31(2), pp. 210-223, https://doi.org/10.1177/1473095213499216.

DuBois, T. D. (2012) 'Should You Trust Academic Celebrities?', The Huffington Post, 22 August. http://www.huffingtonpost.com/thomas-daviddubois/paul-krugman-niall-ferguson_b_1820236.html

Expert Connect (2019) 'Expert Connect: Connecting industry with research expertise', expertconnect.global, n.d. https://expertconnect.global/about

Lamont, M. (1987) 'How to become a dominant French philosopher: The case of Jacques Derrida', American Journal of Sociology, 93(3), pp. 584-622, https://doi.org/10.1086/228790.

Miles, R. (2012) 'The rise of the Super Profs: should we be worried about celebrity academics?', The Conversation, 15 November.

http://theconversation.com/the-rise-of-the-super-profs-should-we-beworried-about-celebrity-academics-10613

Science Media Center (2019) 'How we work: Good Judgement = science* journalism². That's our formula', Sciencemediacenter.de, n.d. https://www.sciencemediacenter.de/en/smc/what-we-do/

Shea, C. (2014) 'The New Academic Celebrity: Why a different kind of scholar and idea - hits big today', The Chronicle of Higher Education, 14 April. http://www.chronicle.com/article/The-New-Academic-Celebrity/145845/

Tickle, L. (2012) 'So you want to be the new Brian Cox? ... How to become a celebrity academic', The Guardian, 15 May.

https://www.theguardian.com/education/2012/may/14/celebrity-academicradio-tv-funding

Walsh, P. W. (2015) 'On Academic Celebrity', The Sociological Review, 9 October. https://www.thesociologicalreview.com/blog/on-academiccelebrity.html

Wishcrys. (2017) 'MeituXiuxiu, Cultural diffusion, and Asia exotica', wishcrys.com, 19 January. https://wishcrys.com/2017/01/19/meituxiuxiucultural-diffusion-and-asia-exotica/ 